\title{
False-positive colloidal gold-based immunochromatographic strip assay reactions for antibodies to SARS-CoV-2 in patients with autoimmune diseases
}

\author{
Xiumei Xiao" ${ }^{1 \#}$, Qingtao Zhou ${ }^{2 \#}$, Jinghao Zhu ${ }^{1}$, Lin Sun ${ }^{3}$, Hua Zhang ${ }^{4}$, Yongchang Sun ${ }^{2}$, Jinxia Zhao ${ }^{3}$, \\ Liyan Cui ${ }^{1}$
}

${ }^{1}$ The Department of Laboratory Medicine, Peking University Third Hospital, Beijing, China; ${ }^{2}$ The Department of Respiratory and Critical Care Medicine, Peking University Third Hospital, Beijing, China; ${ }^{3}$ The Department of Rheumatology and Immunology, Peking University Third Hospital, Beijing, China; ${ }^{4}$ Research Center of Clinical Epidemiology, Peking University Third Hospital, Beijing, China

Contributions: (I) Conception and design: L Cui, Q Zhou, X Xiao, J Zhao; (II) Administrative support: L Cui, Q Zhou, J Zhao, Y Sun; (III) Provision of study materials or patients: L Cui, X Xiao, Q Zhou, J Zhao, L Sun; (IV) Collection and assembly of data: X Xiao, J Zhu, L Sun, H Zhang; (V) Data analysis and interpretation: L Cui, X Xiao, Q Zhou, H Zhang, J Zhao; (VI) Manuscript writing: All authors; (VII) Final approval of manuscript: All authors.

"These authors contributed equally to this work.

Correspondence to: Liyan Cui, MD. Department of Laboratory Medicine, Peking University Third Hospital, No. 49, Hua Yuan Bei Lu, Haidian District, Beijing 100191, China. Email: cliyan@163.com; Jinxia Zhao, MD. Department of Rheumatology and Immunology, Peking University Third Hospital, Beijing 100191, China. Email: zhao-jinxia@163.com.

Background: The outbreak of the novel 2019 coronavirus disease (COVID-19) was declared a global pandemic by the World Health Organization (WHO) on March 11, 2020. The diagnosis of COVID-19 is frequently based on a positive serological test. We noted the occurrence of false-positive results for COVID-19 in the colloidal gold-based immunochromatographic strip (ICS) assay in sera from patients with autoimmune diseases (ADs). This study aimed to evaluate the possible reasons for the false-positive results in two ICS assays (Wondfo ICS and Innovita ICS) and to investigate the effect of urea dissociation in reducing false-positive results.

Methods: The sera of 135 patients with ADs, 13 confirmed COVID-19 patients, 95 disease controls, and 120 healthy controls were tested for immunoglobin $\mathrm{M}(\mathrm{IgM})$ and $\operatorname{IgG}$ against severe acute respiratory syndrome coronavirus 2 (SARS-CoV-2) using Wondfo and Innovita ICS kits. The distributions of auto-antibodies in antibody-positive and antibody-negative groups were also compared, and bivariable logistic regression was used to assess auto-antibodies associated with false-positive results. A urea dissociation test of ICS was performed for the SARS-CoV-2 antibody-positive samples.

Results: Specificity of Wondfo ICS for the 95 disease controls was $94.74 \%$ compared to $98.95 \%$ and 96.84\% for Innovita SARS-CoV-2 IgM and IgG, respectively. Specificity of Wondfo ICS for the 120 healthy controls was $97.5 \%$ compared to $100 \%$ and $99.17 \%$ for Innovita SARS-CoV-2 IgM and IgG, respectively. Specificity of Wondfo ICS for AD patients was $73.33 \%$ compared to $97.78 \%$ and $96.30 \%$ for Innovita SARS-CoV-2 IgM and IgG, respectively. Sensitivity was $74.07 \%$ for Wondfo compared to $70.37 \%$ for Innovita IgM and $66.67 \%$ for Innovita IgG. Using the Wondfo ICS, the percentage of elevated rheumatoid factor $(\mathrm{RF})$ level (>20 IU/mL) was higher in the SARS-CoV-2 antibody-positive group compared with the antibody-negative group [27/36 (75.0\%) vs. 34/99 (34.34\%), $\mathrm{P}=0.001]$. The elevated RF was associated with antibody positivity, with an odds ratio of 4.671 [95\% confidence interval (CI), 1.88-11.69]. The specificity of the Wondfo ICS assay for the AD patients was increased from $73.33 \%$ to $94.07 \%$ after the urea dissociation assay.

Conclusions: An elevated serum RF level could lead to false-positive results when detecting SARS-CoV-2 antibodies using the Wondfo ICS kit, and the urea dissociation assay would be helpful in reducing the incidence of false-positive results. 
Keywords: SARS-CoV-2; false-positive; gold-based immunochromatographic strip assay; rheumatoid factor; urea

Submitted Sep 18, 2020. Accepted for publication Jan 15, 2021.

doi: 10.21037/atm-20-6509

View this article at: http://dx.doi.org/10.21037/atm-20-6509

\section{Introduction}

The outbreak of coronavirus disease 2019 (COVID-19) was declared a global pandemic by the World Health Organization (WHO) on March 11, 2020 (1), and the subsequent global spread of COVID-19 continues as evidenced by the rapid increase in the number of reported cases $(2,3)$. Prompt infection control measures and public health surveillance to prevent the spread of COVID-19 rely on the early and accurate diagnosis of the disease. Thus, a rapid and accurate diagnostic test is needed to implement necessary quarantine measures and interventions $(4,5)$. A failure to effectively diagnose COVID-19 may have serious implications not only for individual patients but also for public health.

Currently, severe acute respiratory syndrome coronavirus 2 (SARS-CoV-2) nucleic acid real-time reverse transcription polymerase chain reaction (RT-PCR) is the key method in COVID-19 diagnosis and treatment $(6,7)$. However, the sampling site, sampling skills, and viral load can significantly impact the sensitivity of the nucleic acid test (8), and falsenegative results have been reported in recent studies (9). Serological tests such as enzyme-linked immunosorbent assay (ELISA), immunofluorescence assay (IFA), colloidal gold-based immunochromatographic strip (ICS), and neutralization tests are effective in detecting an immune response to the virus and can be used in epidemiological investigation and population immunity assessment $(10,11)$. Among them, the ICS assay is a rapid and convenient onestep immunochromatographic assay which is often used for rapid point-of-care screening of anti-SARS-CoV-2 immunoglobin $M$ ( $\operatorname{IgM}$ ) and IgG. Detection of ICS antiSARS-CoV-2 antibodies in blood samples can provide a quick and simple diagnostic method for suspected patients, with varied reported sensitivity 14 days after the onset of symptoms (24.5-100\%) and specificity (90.1-100\%) (12-15). However, serological testing is often limited by its potential cross-reactivity with antibodies caused by other coronaviruses and/or non-specific antibodies from past exposures $(10,16)$.

Recently, we noted the occurrence of false-positive results in the ICS assay of sera from patients with autoimmune diseases (ADs). The immune system in patients with $\mathrm{ADs}$ produces a variety of auto-antibodies such as rheumatoid factor (RF), anti-cyclic citrullinated peptide (anti-CCP), and antinuclear antibodies (ANA), which may lead to crossreactivity and false-positive results in serological testing (17). However, until now, the subject of false-positive results and cross-reactivity in the sera of patients with ADs remain unexplored. Patients with ADs are vulnerable to various viruses because their immunity is weakened by the use of immunosuppressants. Therefore, investigation of the causes for false-positive results is helpful in improving the clinical diagnosis and management of these patients. The falsepositive results of immunoassays are frequently caused by the bindings of auto-antibodies, heterophilic antibodies and complements in serum to antibodies in the detection kit, but these bindings are often nonspecific and weaker than those of specific reactions. Some studies have found that interactions of this type can be reduced or eliminated by the addition to assay tests of a certain concentration of urea, which is a dissociating substance between nonspecific antigen-antibody reactions $(18,19)$.

The ICS assay has been widely applied in the diagnosis of COVID-19. This study was conducted to determine the possible reasons for the false-positive results of ICS assay in $\mathrm{AD}$ patients and to investigate the effect of urea dissociation in reducing false-positive results. We present the following article in accordance with the MDAR checklist (available at http://dx.doi.org/10.21037/atm-20-6509).

\section{Methods}

\section{Patients and samples}

We measured SARS-CoV-2 IgM and IgG antibodies in 4 different cohorts: first group of 27 samples from 13 SARSCoV-2 RT-PCR confirmed COVID-19 patients; a group of 120 healthy blood donors; a "disease control" group of 95 patients and a group of $135 \mathrm{AD}$ patients. Serum samples from the participants were collected from the residual samples for the clinical routine, aliquoted, and then stored 
at $-80{ }^{\circ} \mathrm{C}$ for further analysis. The study was conducted in accordance with the Declaration of Helsinki (as revised in 2013) and was approved by the Ethics Committee of Peking University Third Hospital (No. YLS2020-171-01) and individual consent for this retrospective analysis was waived.

Serum samples from the COVID-19 group were obtained from 13 patients (the number of samples obtained from each individual patient ranged from 1 to 4 samples) at different time points during the disease course from February to April 2020. The patients were confirmed with COVID-19 by RT-PCR on nasopharyngeal swabs. To assess specificity, we collected 95 serum samples from 95 patients as control. These included (I) a disease control group of 60 patients with fever and/or respiratory infection but negative result of SARS-CoV-2 RT-PCR test in March 2020; (II) 13 samples from patients with influenza A or B virus infection (Wondfo rapid antigen test) in the period January to February 2019; (III) 10 Cytomegalovirus (CMV) IgM positive serum samples, 7 Rubella virus (RV) IgM positive serum samples and 5 Epstein-Barr virus (EBV) IgM positive serum samples collected from patients in March 2020. In addition, 120 serum samples from 120 healthy adults were evaluated to validate the performance of the ICS assay. The healthy controls were the hospital staff who undergone the yearly physical examination in October 2019, and had no complaints about health issues. All the healthy and disease controls were confirmed to be negative for COVID-19 by RT-PCR, and also confirmed without ADs.

The 135 AD patients were hospitalized at the Department of Rheumatology and Immunology, Peking University Third Hospital from January to November 2019, fulfilled the diagnostic criteria for ADs as defined by the American College of Rheumatology (ACR). The AD patients consisted of 7 with anti-synthetase syndrome (ASS), 7 with dermatomyositis (DM), 18 with systemic sclerosis (SSc), 14 with undifferentiated connective tissue disease (UCTD), 31 with rheumatoid arthritis (RA), 29 with systemic lupus erythematosus (SLE), and 29 with Sjögren syndrome (SS), none were infected by SARS-CoV-2 according to their clinical features, laboratory examinations and imaging manifestations.

\section{ICS test and urea dissociation test}

Two ICS test kits certified by the National Medical Products Administration were used. The first was used to detect total SARS-CoV-2 antibodies (Wondfo ICS, Wondfo
Biotech Ltd., Guangzhou, China, lot no. W19500207), while the second was used to separately detect IgG and IgM antibodies (Innovita ICS, Innovita Biotech Ltd., Tangshan, China, lot no. 20200406). To perform each assay, a $10 \mu \mathrm{L}$ serum sample and 2 drops of sample diluent were added to the sample pad, and the results in the " $\mathrm{T}$ " land " $\mathrm{C}$ " lines were observed after $15 \mathrm{~min}$. The SARS-CoV-2 antibody in the sample bound first with the SARS-CoV-2 recombinant antigen labeled by colloidal gold, and was then captured by the anti-human-IgM ( $\mu$-chain specific) and $\operatorname{IgG}$ at the test line $(\mathrm{T})$ position. A lack of the control line showing on the card indicated that the test was invalid. To investigate the effect of freezing on the results of these samples, we repeated the ICS test on 15 positive and 15 negative serum samples that had been frozen at $-80{ }^{\circ} \mathrm{C}$ for 5 months and found that the results were the same as when previously measured.

A urea dissociation test of the ICS assay was performed for each SARS-CoV-2 antibody-positive sample according to the method proposed by Wang et al. with a small modification (18). Briefly, a $10 \mu \mathrm{L}$ serum sample and 2 drops of sample diluent were added to the sample hole of the test card. When the liquid was about to reach the upper absorbent paper, $100 \mu \mathrm{L}$ of phosphate-buffered saline (PBS) solution containing $6 \mathrm{~mol} / \mathrm{L}$ urea was added into the sample hole, and the results were observed for 20 to $25 \mathrm{~min}$. Duplication of the test was conducted to verify the results.

\section{Autoantibody detection}

ANAs were detected by IFA (Euroimmun, Lubeck, Germany). Serum IgG, IgA, IgM, and total RF was evaluated by a nephelometry assay (Immage 800, BeckmanCoulter, Brea, CA, USA), and the anti-CCP antibodies were assessed using an electrochemiluminescent immunoassay (ECLIA; Roche Diagnostics, Mannheim, Germany). Values above $20 \mathrm{IU} / \mathrm{mL}$ and $10 \mathrm{U} / \mathrm{mL}$ were considered positive for RF and anti-CCP, respectively. Other autoantibodies were detected by immunoblot assay (Euroimmun, Lubeck, Germany) including antibodies to Sjögren's syndrome A 52 (SSA52), SSA, SSB, polymyositis-scleroderma antibodies (PM-Scl), proliferating cell nuclear antigen (PCNA), Smith antigen/nuclear ribonucleoprotein $(\mathrm{Sm} / \mathrm{RNP})$, ribosomal ribonucleoproteins (rRNP), Jo-1, scleroderma-associated antigen (Scl-70), double-stranded (ds) DNA, antihistone antibodies (AHA), anti-nucleosome antibody (ANUA), anti-centromere protein $\mathrm{B}$ antibodies (CENPB) and anti- 
mitochondrial antibody M2 (AMA-M2).

\section{RT-PCR specific for SARS-CoV-2}

SARS-CoV-2 viral RNA was detected in nasopharyngeal swabs of COVID-19 patients and controls. RNA was extracted from a $200 \mu \mathrm{L}$ mixture using an automatic nucleic acid extraction instrument and magnetic bead method nucleic acid extraction kit (Nextractor 48, Seoul, South Korea). Detection of SARS-CoV-2 was performed with a commercial quantitative RT-PCR assay kit (Bojie, Shanghai, China). Primers and probes targeting SARS-CoV-2 open reading frame $(\mathrm{ORF} 1 \mathrm{a} / \mathrm{b})$ and nucleocapsid $(\mathrm{N})$ genes were used in the RT-PCR kit. The RT-PCR reactions were conducted in a thermal cycler (ABI7500 Real-Time PCR System, Applied Biosystems, USA) under the following conditions: $50^{\circ} \mathrm{C}$ for $10 \mathrm{~min}$ for reverse transcription, followed by $95^{\circ} \mathrm{C}$ for $5 \mathrm{~min}$ and then 40 cycles of $95^{\circ} \mathrm{C}$ for $10 \mathrm{~s}$, and $55^{\circ} \mathrm{C}$ for $40 \mathrm{~s}$. Samples with a cycle threshold (Ct) value below 38 were identified to be positive.

\section{Statistical analysis}

Statistical analyses were performed with SPSS 19.0 software (IBM Corp., Armonk, NY, USA). Continuous variables with abnormal or normal distribution were expressed as the medians ( $25 \%$ quartile, $75 \%$ quartile) or mean $( \pm$ standard deviation), respectively, and categorical variables are summarized as counts (percentages). A two-sample independent $t$ test was used to compare the differences between two groups for continuous variables with normal distribution, and a nonparametric test (Mann-Whitney $U$ tests) was used for continuous variables with abnormal distribution. We performed Pearson's $\chi^{2}$ tests or Fisher's exact test for the difference of proportions for categorical variables. Variables with a $\mathrm{P}$ value of $<0.10$ were included as candidates for the bivariable logistic regression to assess autoantibodies associated with false-positive results of SARS-CoV-2 antibodies. Missing data were excluded, and 2 -sided $\mathrm{P}$ values $<0.05$ were defined as statistically significant.

\section{Results}

\section{Detection of SARS-CoV-2 antibodies by the Innovita and Wondfo ICS assay}

The healthy control group consisted of 42 male and 78 female with a mean age of 49.2 years (range 23-65 years). Specificity of Wondfo ICS kit in healthy control group was $97.5 \%$, and was lower than that of Innovita ICS assay, which had a $100 \%$ specificity for IgM and $99.17 \%$ for IgG antibody (Table 1). The mean age of 13 COVID-19 patients was 54.3 (range, 25 to 73 years), with a majority being female $(53.84 \%)$. Sensitivity was $74.07 \%$ for Wondfo compared to $70.37 \%$ for Innovita $\operatorname{IgM}$ and $66.67 \%$ for Innovita IgG. The diagnostic sensitivity was $68.18 \%$ for Wondfo compared to $63.64 \%$ for Innovita IgM and $59.09 \%$ for Innovita $\mathrm{IgG}$ within 14 days of symptom onset. The diagnostic sensitivity reached to $100 \%$ after 2 weeks of symptom onset for the two ICS rapid tests (Table 1). The disease control group consisted of 44 male and 51 female with a mean age of 51.2 years (range 19-72 years). Specificity of Wondfo ICS for 95 disease controls was $94.74 \%$ compared to $98.95 \%$ and $96.84 \%$ for Innovita SARS-CoV-2 IgM and IgG.

The $\mathrm{AD}$ disease group consisted of 17 male and 118 female with a mean age of 52.5 years (range $17-83$ years). Thirtysix $\mathrm{AD}$ patients (26.67\%) tested positive for total antibodies for SARS-CoV-2 according to the Wondfo ICS assay, while five $\mathrm{AD}$ patients $(3.70 \%)$ tested positive for IgG and three patients $(2.22 \%)$ tested positive for IgM using the Innovita ICS assay. The false-positive rate of total SARS-CoV-2 antibodies tested by Wondfo ICS was as high as $41.94 \%$ $(13 / 31)$ in RA patients, followed by $34.48 \%(10 / 29)$ in patients with SS and $28.57 \%(2 / 7)$ in patients with ASS and DM. The positive rates of total antibodies in patients with SLE, SSc and UCTD were 13.79\% (4/29), 16.67\% (3/18), and $14.29 \%(2 / 14)$, respectively (Table 1).

\section{Analysis of auto-antibodies and SARS-CoV-2 antibodies}

While no auto-antibodies were detected in the serum samples of controls or COVID-19 patients, 1 or more auto-antibodies were detected in serum samples from the $135 \mathrm{AD}$ patients. The $\mathrm{AD}$ patients were then divided into 2 groups according to the Wondfo ICS test results: the positive SARS-CoV-2 antibody group and the negative group, Table 2 lists the comparative results of auto-antibodies between the 2 groups. Age and sex were not statistically significantly different among $\mathrm{AD}$ patients positive or negative for antibodies [mean age, 55.3 (SD, 15.6) vs. 52.0 (SD, 15.4) years; $33 / 36(91.67 \%)$ vs. 85/99 (85.86\%) women].

The difference in the distribution of RA patients in SARS-CoV-2 antibody-positive and antibody-negative groups was significant $(\mathrm{P}=0.029)$. The positive rate for 
Table 1 The positive rates of anti-SARS-CoV-2 antibodies in 377 serum specimens before and after urea dissociation

\begin{tabular}{|c|c|c|c|c|c|c|c|}
\hline \multirow{2}{*}{ Group } & \multirow{2}{*}{ No. } & \multicolumn{4}{|c|}{ Innovita ICS } & \multicolumn{2}{|c|}{ Wondfo ICS Total antibody (\%) } \\
\hline & & Before & After & Before & After & Before & After \\
\hline Healthy control & 120 & 0 & - & $1(0.83)$ & 0 & $3(2.5)$ & 0 \\
\hline Disease control & 95 & $1(1.05)$ & $1(1.05)$ & $3(3.16)$ & $1(1.05)$ & $5(5.26)$ & $2(2.11)$ \\
\hline ADs & 135 & $3(2.22)$ & 0 & $5(3.70)$ & 0 & $36(26.67)$ & $8(5.93)$ \\
\hline ASS & 7 & 0 & - & 0 & - & $2(28.57)$ & 0 \\
\hline DM & 7 & 0 & - & 0 & - & $2(28.57)$ & 0 \\
\hline SSc & 18 & $1(5.56)$ & 0 & $1(5.56)$ & 0 & $3(16.67)$ & $1(5.56)$ \\
\hline SLE & 29 & 0 & - & $2(6.90)$ & 0 & $4(13.79)$ & 0 \\
\hline SS & 29 & 0 & - & 0 & - & 10 (34.48) & $4(13.79)$ \\
\hline
\end{tabular}

a , a total of 27 sera were included, of which 22 were collected within 14 days of symptom onset. ADs, autoimmune diseases; ASS, anti-synthetase syndrome; DM, dermatomyositis; SSc, systemic sclerosis; UCTD, undifferentiated connective tissue disease; RA, rheumatoid arthritis; SLE, systemic lupus erythematosus; SS, Sjögren syndrome.

SARS-CoV-2 antibodies in RA patients was higher than in non-RA patients [13/31 (41.94\%) vs. 23/104 (22.12\%)]. The median IgM and IgG levels were significantly lower in the SARS-CoV-2 antibody-negative group compared with the antibody-positive group $(\mathrm{P}=0.001 ; \mathrm{P}=0.040)$. The percentage of elevated $\mathrm{RF}$ level $(>20 \mathrm{IU} / \mathrm{mL})$ was higher in the SARS-CoV-2 antibody-positive group compared with the antibody-negative group [27/36 (75.0\%) vs. 34/99 (34.34\%), $\mathrm{P}=0.001$ ]; similarly, the percentage of lower RF level $(<20 \mathrm{IU} / \mathrm{mL})$ was lower in the antibody-positive group compared with the antibody-negative group [9/36 (25.0\%) vs. 65/99 (65.66\%), $\mathrm{P}=0.001]$. Other auto-antibodies including anti-CCP, ANA, anti-SSA/SSB, anti-SSA52, anti-Sm, anti-rRNP, anti-RNP, ANUA, and anti-ds-DNA showed no significant difference between the SARS-CoV-2 antibody-positive and antibody-negative groups (Table 2).

In the bivariable logistic regression analysis, $\operatorname{IgM}, \operatorname{IgG}$, anti-SSB and anti-ds-DNA in sera of AD patients were not statistically significantly associated with antibody positivity (Table 3). In contrast, elevated RF (>20 IU/mL) was associated with antibody positivity [27/61 (44.26\%) with elevated RF level vs. 9/74 (12.16\%) with normal RF level;
$\mathrm{P}=0.001$ ], with an odds ratio of 4.671 (95\% CI, 1.88-11.69).

\section{Urea dissociation test of the ICS assay}

The urea dissociation test of the Innovita ICS assay was conducted on antibody-positive sera from controls and $\mathrm{AD}$ patients (Figure 1). All the results of SARS-CoV-2 IgM and $\mathrm{IgG}$ analyses from the healthy controls were negative, whereas those from the confirmed COVID-19 patients remained positive (Table 1). One serum sample from a patient with fever and Escherichia coli bacteremia remained positive for SARS-CoV-2 IgM and IgG after urea dissociation test.

The urea dissociation test of the Wondfo ICS assay was conducted on 3 serum samples from healthy control, 5 from disease control and 36 from $\mathrm{AD}$ patients. The results of SARS-CoV-2 antibody analyses of 34 serum samples were negative, whereas those from the COVID-19 patients remained positive (Table 1). The specificity of the Wondfo ICS assay for the AD patients increased from $73.33 \%$ to $94.07 \%$ after the urea dissociation assay. In 27 serum samples positive for SARS-CoV-2 antibody and elevated $\mathrm{RF}$, the SARS-CoV-2 antibody results were negative in 21 
Table 2 Characteristics of auto-antibodies in AD patients tested by the Wondfo ICS assay

\begin{tabular}{|c|c|c|c|c|}
\hline Variable & SARS-CoV-2 antibody-negative $(n=99)^{a}$ & SARS-CoV-2 antibody-positive $(n=36)^{a}$ & $\mathrm{t} / \chi 2 / z$ & $P$ value \\
\hline Female & $85 / 99(85.86 \%)$ & $33 / 36(91.67 \%)$ & 0.809 & 0.368 \\
\hline RA & $18 / 99(18.18 \%)$ & $13 / 36(36.11 \%)$ & 4.797 & 0.029 \\
\hline $\lg \mathrm{M}$ & $0.95(0.63,1.29)$ & $1.23(0.89,1.8)$ & 3.244 & 0.001 \\
\hline $\lg A$ & $2.4(1.77,3.43)$ & $2.37(2.01,3.31)$ & 0.507 & 0.614 \\
\hline \multicolumn{5}{|l|}{$\mathrm{RF}$} \\
\hline$<20 \mathrm{IU} / \mathrm{mL}$ & 65/99 (65.66\%) & $9 / 36(25.0 \%)$ & 17.619 & 0.001 \\
\hline$>20 \mathrm{IU} / \mathrm{mL}$ & $34 / 99(34.34 \%)$ & $27 / 36(75.0 \%)$ & & \\
\hline- & $13 / 99(13.13 \%)$ & $6 / 36(16.67 \%)$ & 1.116 & 0.572 \\
\hline$+(1: 80-1: 160)$ & $19 / 99$ (19.19\%) & 4/36 (11.11\%) & & \\
\hline$+(\geq 1: 320)$ & $67 / 99(67.68 \%)$ & $26 / 36(72.22 \%)$ & & \\
\hline Anti-PM-Scl+ & $1 / 99(1.01 \%)$ & $1 / 36(2.78 \%)$ & 0.565 & 0.452 \\
\hline Anti-Sm+ & 7/99(7.07\%) & $0(0 \%)$ & 2.685 & 0.101 \\
\hline Anti-rRNP+ & $9 / 99(9.09 \%)$ & 1/36 (2.78\%) & 1.534 & 0.215 \\
\hline Anti-RNP+ & 19/99 (19.19\%) & $8 / 36(22.22 \%)$ & 0.152 & 0.697 \\
\hline ANUA+ & 4/99 (4.04\%) & 1/36 (2.78\%) & 0.118 & 0.731 \\
\hline Anti-SSB+ & $5 / 99$ (5.05\%) & $5 / 36(13.89 \%)$ & 3.007 & 0.083 \\
\hline Anti-Jo-1+ & 3/99 (3.03\%) & 1/36 (2.78\%) & 0.006 & 0.939 \\
\hline AMA-M2+ & 2/99 (2.02\%) & 1/36 (2.78\%) & 0.07 & 0.792 \\
\hline Anti-PCNA+ & 1/99 (1.01\%) & $0(0 \%)$ & 0.366 & 0.545 \\
\hline Anti-Scl-70+ & 11/99 (11.11\%) & 2/36 (5.56\%) & 0.936 & 0.333 \\
\hline
\end{tabular}

\footnotetext{
${ }^{a}$, the values represent median (25\% percentile, $75 \%$ percentile), mean \pm SD and numbers with auto-antibodies/total (\%) of cases. RA, rheumatoid arthritis; RF, rheumatoid factor; CCP, cyclic citrullinated peptide; ANA, antinuclear antibodies; PM-Scl, polymyositis-scleroderma antibodies; Sm, Smith antigen; RNP, nuclear ribonucleoprotein; rRNP, ribosomal ribonucleoproteins; ANUA, anti-nucleosome antibody; ds-DNA, double-stranded DNA; CENPB, centromere protein B; AHA, antihistone antibodies; SSA52, Sjögren's syndrome A 52; AMA-M2, anti-mitochondrial antibody M2; PCNA, proliferating cell nuclear antigen; Scl-70, scleroderma-associated antigen.
} 
Table 3 Auto-antibody predictors of SARS-CoV-2 antibodies among AD patients

\begin{tabular}{lcccc}
\hline & \multicolumn{2}{c}{ No. with SARS-CoV-2 antibodies/total (\%) } & Odds ratio $\left(95 \% \mathrm{Cl}^{\mathrm{a}}\right)$ & \\
\cline { 2 - 4 } & Auto-antibody present & Auto-antibody absent & & \\
\hline RF & $27 / 61(44.26)$ & $9 / 74(12.16)$ & $4.671(1.88-11.69)$ & 0.001 \\
Anti-ds-DNA & $1 / 15(6.67)$ & $35 / 120(29.17)$ & $0.225(0.026-1.957)$ & 0.176 \\
Anti-SSB & $5 / 10(50)$ & $31 / 125(24.8)$ & $2.264(0.497-10.31)$ & 0.291 \\
IgG & - & - & $1.013(0.952-1.078)$ & 0.687 \\
IgM & - & - & $1.550(0.963-2.493)$ & 0.071 \\
\hline
\end{tabular}

a, 95\% Cls of the odds ratios based on bivariable logistic regression analyses. RF, rheumatoid factor; ds-DNA, double-stranded DNA; SSB, Sjögren syndrome antigen B.

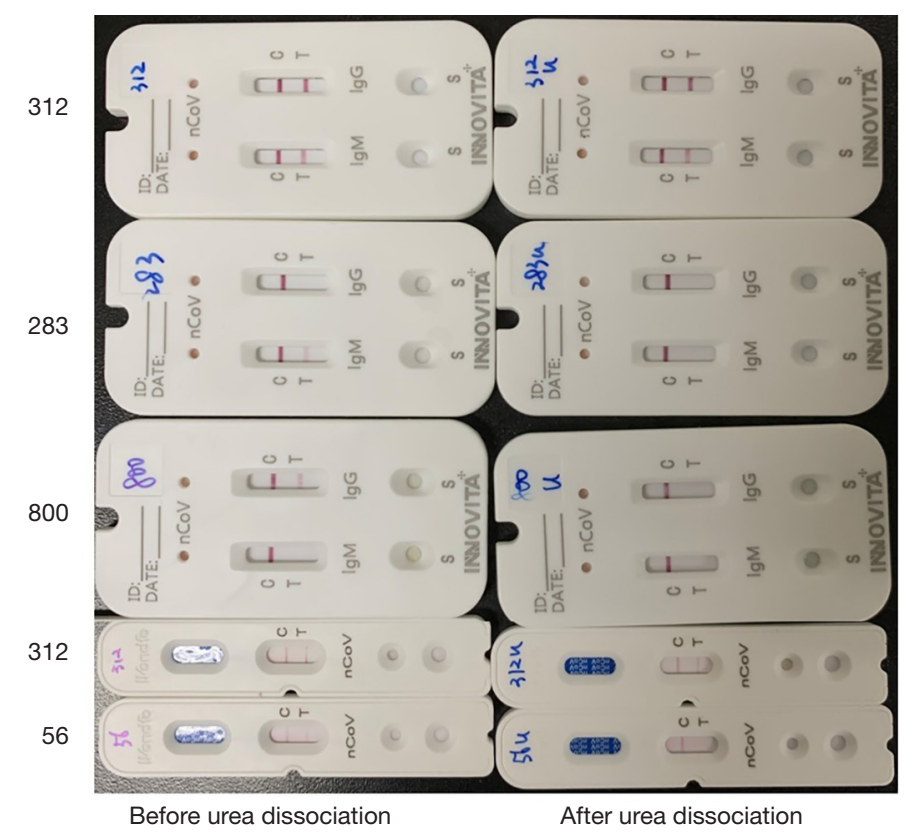

Figure 1 SARS-CoV-2 antibody detected with ICS assay before and after urea dissociation. No. 312, serum from confirmed COVID-19 patients; No. 56, 283 and 800, sera from AD patients.

(77.78\%) samples after urea dissociation. In addition, 7 of 9 serum samples with a normal RF level turned negative.

\section{Discussion}

Rapid and accurate testing for SARS-CoV-2 is needed to allow healthcare providers to make critical patient management decisions (20). Conventional serologic assays for viral-specific IgM and IgG have been proposed to facilitate the diagnosis and infection monitoring of COVID-19, just as they were in the detection of severe acute respiratory syndrome coronavirus (SARS-CoV) $(11,21,22)$. However, serological testing is often limited by its potential cross-reactivity and false-positivity caused by other pathogens and/or non-specific antibodies. The elimination of false-positive tests will greatly assist the serodiagnosis, epidemiological survey, and control of SARS$\mathrm{CoV}-2$, and an understanding of the causes of false-positive tests underpins this effort.

Our study showed that the specificity of the Wondfo ICS for $\mathrm{AD}$ patients was $73.33 \%$ compared to $97.78 \%$ and $96.30 \%$ for the Innovita ICS detecting SARS-CoV-2 IgM 
and $\operatorname{IgG}$, respectively. Patients with ADs have a variety of auto-antibodies, which can cause false-positive results of immunoassay $(17,18)$. Several studies have shown that RF is the most common of these (23-25), and this finding is supported by the results of our study. Our study showed that elevated RF levels ( $>20 \mathrm{IU} / \mathrm{mL})$ were associated with antibody positivity using the Wondfo ICS assay, with an odds ratio of 4.671 (95\% CI, 1.88-11.69). The positive rate of SARS-CoV-2 antibody was significantly higher in the elevated RF group than in the normal RF group (44.26\% vs. $12.16 \%)$. The precise reason why sera containing elevated RF levels causes false-positive results when the Wondfo ICS is used is not clear and requires further research. Interactions may occur between RF and the various components used in ICS, such as colloidal goldlabeled recombinant SARS-CoV-2 antigen and anti-human IgM or IgG antibodies. Methods which may reduce the interference of RF include removal of the Fc fragment of the anti-human IgG antibody, dilution of samples, adding heat-denatured IgG to block the RF, and urea dissociation. The urea dissociation test is simple, easy to perform, and has been shown to be highly effective in reducing falsepositive results of immunoassays associated with $\operatorname{RF}(18,26)$. In our study, we evaluated the effect of urea dissociation in reducing false positives of the ICS assay. Of the 27 sera with elevated RF and positive SARS-CoV-2 antibody tests, 21 turned negative, whereas the serum samples from COVID-19 patients were not affected, meanwhile, 7 of 9 serum samples with normal RF level turned negative. The false-positive results seen in the SARS-CoV-2 antibody were much less common in the Innovita ICS assay in comparison to the Wondfo ICS. Eleven serum samples positive for SARS-CoV-2 IgG or IgM tested negative after urea dissociation, indicating urea dissociation is useful in reducing non-specific interactions and false-positive results due to interfering factors other than RF. In this study, we also evaluated the influence of other auto-antibodies in patients with $\mathrm{ADs}$ on the detection of anti-SARS-CoV-2 IgM ang IgG. There was no significant difference in the distribution of ANA, anti-SSA/SSB, anti-SSA52, antiCENPB, anti-RNP, anti-Scl-70 and anti-ds-DNA between the positive anti-SARS-CoV-2 IgM or IgG group and the negative group, which may indicate that the two test kits are less affected by these auto-antibodies.

While this study is a timely evaluation of the false positivity of Wondfo and Innovita ICS testing kits on COVID-19, it is worth noting some limitations. First, this is a retrospective study and some data were missing or not detected. For example, anti-CCP auto-antibodies were only detected in 29 serum samples. Second, the sample size was small, especially the number of serum samples from patients with COVID-19 and ASS. Finally, the interpretation of the results of the ICS assay was based on the visual observation of the T-line, and some light-colored test bands might have been interpreted as equivocal results. In our study, 30 out of $57(52.63 \%)$ positive bands in control group were interpreted as weak immunoreactivity, 15 out of 57 (26.32\%) positive bands of COVID-19 patients were weak. The accumulated experimental experience will help laboratory staff to interpret the band intensities in T-lines and report accurate results. Further well-designed prospective studies are needed to evaluate the efficacy of ICS assay in patients with different underlying conditions.

\section{Conclusions}

The Innovita ICS assay kit was found to be highly specific in both $\mathrm{AD}$ patients and controls. As a common auto-antibody in patients with $\mathrm{ADs}$, elevated $\mathrm{RF}$ level $(>20 \mathrm{IU} / \mathrm{mL})$ was associated with antibody positivity using the Wondfo ICS assay. These false-positive results can be reduced by urea dissociation, and this should also be considered for the ICS assay.

\section{Acknowledgments}

We would like to thank LetPub (www.letpub.com) and AME for English language assistance (http://editing. amegroups.cn/\#editing) during the preparation of this manuscript.

Funding: This project was funded by National Major Scientific and Technological Special Project from Ministry of Science and Technology (No. 2017ZX09304012005 to LC).

\section{Footnote}

Reporting Checklist: The authors have completed the MDAR checklist. Available at http://dx.doi.org/10.21037/ atm-20-6509

Data Sharing Statement: Available at http://dx.doi. org/10.21037/atm-20-6509

Conflicts of Interest: All authors have completed the ICMJE uniform disclosure form (available at http://dx.doi. org/10.21037/atm-20-6509). The authors have no conflicts 
of interest to declare.

Ethical Statement: The authors are accountable for all aspects of the work in ensuring that questions related to the accuracy or integrity of any part of the work are appropriately investigated and resolved. The study was conducted in accordance with the Declaration of Helsinki (as revised in 2013) and was approved by the Ethics Committee of Peking University Third Hospital (No. YLS2020-171$01)$ and individual consent for this retrospective analysis was waived.

Open Access Statement: This is an Open Access article distributed in accordance with the Creative Commons Attribution-NonCommercial-NoDerivs 4.0 International License (CC BY-NC-ND 4.0), which permits the noncommercial replication and distribution of the article with the strict proviso that no changes or edits are made and the original work is properly cited (including links to both the formal publication through the relevant DOI and the license). See: https://creativecommons.org/licenses/by-nc-nd/4.0/.

\section{References}

1. The Lancet Infectious Diseases. COVID-19, a pandemic or not? Lancet Infect Dis 2020;20:383.

2. Chen L, Liu W, Zhang Q, et al. RNA based mNGS approach identifies a novel human coronavirus from two individual pneumonia cases in 2019 Wuhan outbreak. Emerg Microbes Infect 2020;9:313-9.

3. Eurosurveillance Editorial Team. Updated rapid risk assessment from ECDC on the novel coronavirus disease 2019 (COVID-19) pandemic: increased transmission in the EU/EEA and the UK. Euro Surveill 2020;25:2003121.

4. Corman VM, Landt O, Kaiser M, et al. Detection of 2019 novel coronavirus (2019-nCoV) by real-time RT-PCR. Euro Surveill 2020;25:2000045.

5. Cordes AK, Heim A. Rapid random access detection of the novel SARS-coronavirus-2 (SARS-CoV-2, previously 2019-nCoV) using an open access protocol for the Panther Fusion. J Clin Virol 2020;125:104305.

6. Shirato K, Nao N, Katano H, et al. Development of Genetic Diagnostic Methods for Detection for Novel Coronavirus 2019 (nCoV-2019) in Japan. Jpn J Infect Dis 2020;73:304-7.

7. Chan JF, Yip CC, To KK, et al. Improved molecular diagnosis of COVID-19 by the novel, highly sensitive and specific COVID-19-RdRp/Hel real-time reverse
transcription-PCR assay validated in vitro and with clinical specimens. J Clin Microbiol 2020;58:e00310-20.

8. Zou L, Ruan F, Huang M, et al. SARS-CoV-2 Viral Load in Upper Respiratory Specimens of Infected Patients. N Engl J Med 2020;382:1177-9.

9. Li D, Wang D, Dong J, et al. False-Negative Results of Real-Time Reverse-Transcriptase Polymerase Chain Reaction for Severe Acute Respiratory Syndrome Coronavirus 2: Role of Deep-Learning-Based CT Diagnosis and Insights from Two Cases. Korean J Radiol 2020;21:505-8.

10. Pang J, Wang MX, Ang IYH, et al. Potential Rapid Diagnostics, Vaccine and Therapeutics for 2019 Novel Coronavirus (2019-nCoV): A Systematic Review. J Clin Med 2020;9:623.

11. Wu HS, Chiu SC, Tseng TC, et al. Serologic and molecular biologic methods for SARS-associated coronavirus infection, Taiwan. Emerg Infect Dis 2004;10:304-10.

12. $\mathrm{Wu} \mathrm{JL}$, Tseng $\mathrm{WP}$, Lin $\mathrm{CH}$, et al. Four point-of-care lateral flow immunoassays for diagnosis of COVID-19 and for assessing dynamics of antibody responses to SARSCoV-2. J Infect 2020;81:435-42.

13. Van Elslande J, Houben E, Depypere M, et al. Diagnostic performance of seven rapid IgG/IgM antibody tests and the Euroimmun IgA/IgG ELISA in COVID-19 patients. Clin Microbiol Infect 2020;26:1082-87.

14. Serrano MM, Rodriguez DN, Palop NT, et al. Comparison of commercial lateral flow immunoassays and ELISA for SARS-CoV-2 antibody detection. J Clin Virol 2020;129:104529.

15. Chen SY, Lee YL, Lin YC, et al. Multicenter evaluation of two chemiluminescence and three lateral flow immunoassays for the diagnosis of COVID-19 and assessment of antibody dynamic responses to SARS-CoV-2 in Taiwan. Emerg Microbes Infect 2020;9:2157-68.

16. Maache M, Komurian-Pradel F, Rajoharison A, et al. False-positive results in a recombinant severe acute respiratory syndrome-associated coronavirus (SARS-CoV) nucleocapsid-based western blot assay were rectified by the use of two subunits (S1 and S2) of spike for detection of antibody to SARS-CoV. Clin Vaccine Immunol 2006;13:409-14.

17. Wang Y, Sun S, Shen H, et al. Cross-reaction of SARS$\mathrm{CoV}$ antigen with autoantibodies in autoimmune diseases. Cell Mol Immunol 2004;1:304-7.

18. Wang Q, Du Q, Guo B, et al. A Method To Prevent SARS-CoV-2 IgM False Positives in 
Gold Immunochromatography and EnzymeLinked Immunosorbent Assays. J Clin Microbiol 2020;58:e00375-20.

19. Lachaud L, Calas O, Picot MC, et al. Value of 2 IgG avidity commercial tests used alone or in association to date toxoplasmosis contamination. Diagn Microbiol Infect Dis 2009;64:267-74.

20. Binnicker MJ. Emergence of a Novel Coronavirus Disease (COVID-19) and the Importance of Diagnostic Testing: Why Partnership between Clinical Laboratories, Public Health Agencies, and Industry Is Essential to Control the Outbreak. Clin Chem 2020;66:664-6.

21. Zhou P, Yang XL, Wang XG, et al. A pneumonia outbreak associated with a new coronavirus of probable bat origin. Nature 2020;579:270-3.

22. Woo PC, Lau SK, Tsoi HW, et al. Relative rates of non-pneumonic SARS coronavirus infection and SARS

Cite this article as: Xiao X, Zhou Q, Zhu J, Sun L, Zhang H, Sun Y, Zhao J, Cui L. False-positive colloidal gold-based immunochromatographic strip assay reactions for antibodies to SARS-CoV-2 in patients with autoimmune diseases. Ann Transl Med 2021;9(7):534. doi: 10.21037/atm-20-6509 coronavirus pneumonia. Lancet 2004;363:841-5.

23. Astarita G, Gutierrez S, Kogovsek N, et al. False positive in the measurement of thyroglobulin induced by rheumatoid factor. Clin Chim Acta 2015;447:43-6.

24. Sutton BJ, Corper AL, Sohi MK, et al. The structure of a human rheumatoid factor bound to IgG Fc. Adv Exp Med Biol 1998;435:41-50.

25. Duquerroy S, Stura EA, Bressanelli S, et al. Crystal structure of a human autoimmune complex between IgM rheumatoid factor RF61 and IgG1 Fc reveals a novel epitope and evidence for affinity maturation. J Mol Biol 2007;368:1321-31.

26. Wang Q, Lei Y, Lu X, et al. Urea-mediated dissociation alleviate the false-positive Treponema pallidumspecific antibodies detected by ELISA. PLoS One 2019;14:e0212893. 